\title{
Abrupt weaning reduces postweaning growth and is associated with alterations in gastrointestinal markers of development in dairy calves fed an elevated plane of nutrition during the preweaning period
}

\author{
M. A. Steele, ${ }^{*} \dagger^{1}$ J. H. Doelman, ${ }^{*}$ L. N. Leal, $\ddagger$ F. Soberon, $\S$ M. Carson, ${ }^{*}$ and J. A. Metcalf* \\ *Trouw Nutrition AgResearch, Guelph, Ontario, Canada N1G 4T2 \\ †Department of Agricultural, Food and Nutritional Science, University of Alberta, Edmonton, Alberta, Canada T6G 2P5 \\ $\ddagger$ Trouw Nutrition Research and Development, PO Box 220, 5830 AE, Boxmeer, the Netherlands \\ §Shur-Gain USA, Strykersville, NY 14145
}

\section{ABSTRACT}

The benefits of feeding elevated quantities of milk to dairy calves have been well established. However, there is a reluctance to adopt this method of feeding in commercial dairy production because of concerns around growth, health, and ruminal development during weaning. The objective of this study was to characterize the effect of an abrupt (0 d step-down) or gradual (12 d step-down) feeding scheme when calves are fed an elevated plane of nutrition (offered $1.35 \mathrm{~kg}$ of milk replacer/d). For this experiment, a total of 54 calves were randomly assigned to an abrupt or a gradual weaning protocol before weaning at $48 \mathrm{~d}$ of life. Calves were housed and sampled in individual pens for the duration of the experiment, and milk, starter, and straw intake were measured on a daily basis. Body weight was measured every $6 \mathrm{~d}$, whereas blood, rumen fluid, and fecal samples were collected on d 36 (prestep-down), 48 (preweaning), and 54 (postweaning) of the experiment. Although the growth rates of the step-down calves were lower from d 37 to weaning ( 0.62 \pm 0.04 vs. $1.01 \pm 0.04 \mathrm{~kg} / \mathrm{d})$, the postweaning average daily gain was greater compared with the group that was abruptly weaned $(0.83 \pm 0.06$ vs. $0.22 \pm 0.06$ $\mathrm{kg} / \mathrm{d}$ ). Total ruminal volatile fatty acid was greater in the step-down group on the day of weaning (d 48; 59.80 \pm 2.25 vs. $45.01 \pm 2.25 \mathrm{mmol}$ ), whereas the fecal starch percentage was lower during postweaning compared with the abruptly weaned calves (d 54; $3.31 \pm 0.76$ vs. $6.34 \pm 0.76 \%$ ). Analysis of the digestive tract of bull calves on d 55 revealed minimal differences between gross anatomy measurements of gut compartments as well as no morphological differences in rumen papillae development, yet the total mass of rumen when full of

Received November 15, 2016.

Accepted March 27, 2017.

${ }^{1}$ Corresponding author: masteele@ualberta.ca contents was larger in the step-down calves $(7.83 \pm 0.78$ vs. $6.02 \pm 0.78 \mathrm{~kg}$ ). Under the conditions of this study, the results showcase the benefits of a step-down feeding strategy from an overall energy balance standpoint, due to increased adaptation of the gastrointestinal tract preweaning.

Key words: calves, weaning, gastrointestinal development

\section{INTRODUCTION}

In conventional production systems, dairy calves have traditionally been restricted to milk intake at levels less than half of their voluntary milk intake $(\sim 10 \%$ of birth weight). The rationale for this approach is to encourage solid feed intake, rumen development, and early weaning, which generally reduces the costs for raising calves. In contrast, research investigating elevated milk feeding schemes shows longer term benefits, which challenges the traditional approach of restricted milk feeding. For example, feeding calves elevated levels of milk $(\sim 20 \%$ of birth weight) has been shown to improve health, growth rates, feed efficiency, and lifetime production (Soberon et al., 2012). The implementation of elevated milk feeding schemes has increased over the past decade; however, the majority of producers are hesitant to adopt this strategy due to concerns that feeding elevated milk will decrease solid feed intake and rumen development, resulting in depressed growth and health of dairy calves during weaning (Khan et al., 2011, 2016).

To offset the challenges of weaning from elevated milk feeding, a strategy termed the "step-down" was developed, denoting a timed decrease in the amount of milk offered to create a gradual weaning process. To our knowledge, the first example of a step-down protocol was reported by Khan et al. (2007) in a study that showed increased solid feed intake and growth during weaning in step-down calves fed an elevated plane of nutrition compared with conventionally fed, abruptly weaned calves. In the dairy industry, the definition of 
step-down encompasses all levels of nutrition, different durations of the steps, and different methods of reducing the milk intake (Vasseur et al., 2010). Most studies investigating step-down protocols from elevated feeding schemes use automated calf feeding systems that feed calves at higher frequencies $(>4$ times/d) and can program equally distributed reductions through the duration of the step-down. For example, Sweeney et al. (2010) studied the duration of the step-down and noted that calves fed large amounts of milk via an automated feeder ( $>4$ meals/d with a gradual stepdown) displayed better pre- and postweaning intake and higher BW when the duration of the step-down was $10 \mathrm{~d}$ compared with 4 and $0 \mathrm{~d}$. However, a limited number of studies have investigated weaning strategies from elevated planes of nutrition when calves are fed 2 times per day, which is the most common method of feeding in the dairy industry (Vasseur et al., 2010). In addition, there is a large knowledge gap regarding how weaning protocols affect gastrointestinal development. Most research related to characterizing the structural and functional adaptations of the gastrointestinal tract of calves during weaning has been conducted with calves fed a low plane of milk nutrition preweaning.

Therefore, the objective of this study was to examine the effects of gradual (step-down) compared with abrupt weaning on energy intake, growth, and gastrointestinal development during pre- and postweaning when calves are fed an elevated plane of nutrition in 2 meals per day. We hypothesized that calves fed elevated planes of nutrition and weaned gradually consume more energy in solid feed intake and have less weight loss during postweaning through a more rapid development of the ruminant gastrointestinal tract.

\section{MATERIALS AND METHODS}

The study was conducted at the Trouw Nutrition Agresearch Dairy facility (Burford, Ontario, Canada). All animal procedures were approved by the Trouw Nutrition Agresearch Animal Care Committee in accordance with the Canadian Council on Animal Care (2009) guidelines and the experiment was performed over 6 mo (April-September). The dairy calf facility consisted of one room with natural and positive pressure ventilation. Each calf was housed in an individual pen $(245 \mathrm{~cm} \times 121 \mathrm{~cm})$ and bedded daily with wood shavings at $1000 \mathrm{~h}$.

\section{Experimental Treatments, Feeding, and Growth Measurements}

A total of 54 calves (20 female and 34 male calves) were housed in individual pens from birth to the end of the study (d 54). Calves were blocked by sex and randomly assigned to an abrupt (0 d step-down) or gradual weaning strategy (12 d step-down initiated at d 36 with a $50 \%$ reduction of milk until d 48) before complete milk replacer withdrawal at $48 \mathrm{~d}$ of life. All calves received at least $3 \mathrm{~L}$ of their dam's colostrum through a nipple bottle (Super Calf Nipple, Merrick's, Middleton, WI) within $2 \mathrm{~h}$ of calving and transition milk thereafter for the next 2 d of life. On d 3 and 4 , all calves were transitioned to milk replacer (ShurGain Optivia Advantage, 26\% CP, $16 \%$ crude fat, and $45 \%$ lactose, Nutreco Canada Inc., Guelph, ON, Canada) offered at $4.5 \mathrm{~L}$ of milk replacer per feeding $(150 \mathrm{~g} / \mathrm{L}$ resulting in $1.35 \mathrm{~kg} / \mathrm{d}$ ) and fed at 0600 and $1700 \mathrm{~h}$ using nipple pails from d 4 to the initiation of weaning (d 36). The milk replacer raw material consisted of skim milk powder, sweet whey powder, vegetable oils, delactosed whey powder, and premix. All calves had ad libitum access to calf starter (Optivia Advantage Calf Starter, $22 \%$ CP, $28 \%$ starch; $4 \%$ crude fat, $5 \%$ crude fiber containing a 3-mm base pellet, steam-flaked corn, oats, molasses, and soy oil, Nutreco Canada Inc.), chopped straw ( $8 \% \mathrm{CP}, 3-\mathrm{cm}$ chop length), and water from d 7 to 54 , and daily orts were recorded for each feedstuff for the duration of the experiment. Body weights were recorded at $1000 \mathrm{~h}$ for both sexes every sixth day until d 54. Because bull calves were killed on d 55 (described below), additional feed intake measurements for female calves were taken until d 60 and BW on d 60 and 90 of life.

\section{Ruminal $\mathrm{pH}$ and VFA, Blood BHB, and Fecal Starch}

Ruminal fluid, blood, and fecal samples were collected from each calf on d 36, 48 and 54 of the experiment. To assess ruminal fermentation, ruminal fluid was analyzed for $\mathrm{pH}$ and VFA concentration. Ruminal $\mathrm{pH}$ was collected using a Geishauser probe (Geishauser, 1993; Duffield et al., 2004) 3 to $4 \mathrm{~h}$ after the morning feeding $(1000 \mathrm{~h})$, as described by Benschop and Cant (2009). Ruminal fluid was immediately acidified in $0.6 \mathrm{M} \mathrm{HCl}$, placed in liquid nitrogen and stored at $-80^{\circ} \mathrm{C}$ until analysis. Volatile fatty acid concentrations were measured by GC (GC3400, Varian Canada, Mississauga, ON, Canada) with 2-ethylbutyric acid as an internal standard (Green et al., 1999). After the rumen fluid samples were frozen in liquid nitrogen, and the $\mathrm{pH}$ of the original sample was measured as an indicator of ruminal fermentation in less than 1 min after sampling using a $\mathrm{pH}$ meter calibrated before each reading (310 Oakton Instruments, Vernon Hills, IL).

Blood was collected via jugular venipuncture into a 6-mL sodium heparin vacutainer (Becton Dickinson, Franklin Lakes, NJ). After collection, blood was im- 
mediately stored on ice and centrifuged for $20 \mathrm{~min}$ at $3,000 \times g$ at $4{ }^{\circ} \mathrm{C}$. Plasma was separated and stored at $-20^{\circ} \mathrm{C}$ until analysis for BHB using spectrophotometry, as described by Williamson et al. (1962).

Fecal samples (50 g) were collected on d 36,48 , and 54 , frozen immediately, and stored at $-20^{\circ} \mathrm{C}$ until analysis. To facilitate the collection of a fecal sample, calves were rectally finger-stimulated with a sterile-gloved hand. Fecal samples were dried at $60^{\circ} \mathrm{C}$ for $48 \mathrm{~h}$ before grinding to a $1.0-\mathrm{mm}$ particle size. Fecal starch content was determined at Cumberland Valley Analytical Services (Hagerstown, MD) using methods described by Hall (2009) as an indicator of starch digestibility.

\section{Gastrointestinal Dissections and Rumen Papillae Morphology}

All bull calves were killed by captive bolt stunning and exsanguination and their gastrointestinal tract was dissected. The total weights of the forestomach (rumen, reticulum, omasum, and abomasum) and lower gut (duodenum, jejunum, ileum, cecum, and colon) were weighed when full of digesta and when emptied. The individual compartments of the forestomach were cut apart using surgical scissors, and the weights of the sections before and after removing the digesta were recorded. The lower gut was dissected into the small intestine (pyloric sphincter to the proximal ileocecal junction), cecum (proximal ileocecal junction to the colonic junction), and the remaining large intestine (rectum excluded). The empty and full weights of each section were recorded. Through the dissection process, the visceral fat (only evident in the small and large intestine and surrounding the pancreas) was removed using surgical scissors. The length of the small intestine, cecum, and large intestine was measured on a large, flat surface to ensure that the tissue was not stretched.

To assess rumen development, rumen papillae morphology was examined using the classical stereology measurements and a new method called micro-computed tomography (CT) from the ventral sac region, as described by Steele et al. (2014). In brief, tissue was immediately fixed in 10\% neutral buffered formalin for $48 \mathrm{~h}$ then stored in $70 \%$ ethanol at $4^{\circ} \mathrm{C}$ before processing. Tissue sections of $1-\mathrm{cm}^{2}$ were sliced into 4 equal sections of $250 \mu \mathrm{m}$ thickness using a microtome blade. Each section of tissue was examined and imaged under a stereomicroscope equipped with a video camera using $15 \times$ magnification. Measurements of papillae length and width were recorded 2-dimensionally using Northern Eclipse Morphometry Software Version 5.15.4.0 (Empix Imaging, Mississauga, ON, Canada). Only intact rumen papillae not damaged by microtome slicing were measured in all 5 sections. The bottom of the papillae was defined by the dark line delineating the epithelium from the connective tissue at the base of the papillae.

Additionally, a $1-\mathrm{cm}^{2}$ tissue section from the ventral sac of all bull calves was tensioned on a tailored curved plastic holder (Steele et al., 2014), exposed to mercury chloride for micro-CT contrast enhancement and imaged at $45 \mu \mathrm{m}$ resolution for $56 \mathrm{~min}$ using a GE Locus Explore micro-CT (General Electric, Milwaukee, WI). MicroView V2.2 software (General Electric) was used to create a 3-dimensional virtual model of the entire sample. Papillae height and width was measured from the 10 papillae section and the overall density and surface was automatically calculated using MicroView 2.2 in a defined region of interest (Steele et al., 2014).

\section{Calf Management Protocols}

The treatment of disease followed the standard operating procedures at the Trouw Nutrition Agresearch Dairy Facility. Once diarrhea was detected, calves with a fecal score above 2 (McGuirk and Peek, 2014) with milk refusals were treated with a $1-\mathrm{mL}$ subcutaneous injection of meloxicam solution (Metacam, Boehringer Ingelheim, Burlington, ON, Canada) and oral electrolyte therapy (Calf Lyte II, Vetoquinol, Lavaltrie, QC, Canada) until scouring subsided. For respiratory disease, calves were treated with florfenicol solution (NuFlor, Merck Animal Health, Kenilworth, NJ) as per manufacturers' directions. All calves were disbudded at age of $21 \mathrm{~d}( \pm 3 \mathrm{~d})$ using an electric cauterizer (Rhinehart X30, Rhinehart, Spencerville, IN). At least 30 min before disbudding, each calf was given a 1-mL subcutaneous injection of meloxicam solution (Metacam). The cornual nerve block procedure in which 5 $\mathrm{mL}$ of lidocaine solution (Lido-2, Rafter 8, Calgary, $\mathrm{AB}$, Canada) per horn was injected 20 min before cauterizing to minimize pain.

\section{Statistical Analysis}

Intake of ME, starter intake, chopped straw intake, and ADG was analyzed separately for the preweaning period (d 1 to 48 of the study). Data were subjected to ANOVA using the MIXED procedure of SAS 9.1 (SAS Institute Inc., 2004) with time (week) as repeated measures for starter intake, ME intake, chopped straw intake, and ADG.

Data were analyzed as repeated measures using the MIXED procedure of SAS 9.1 (SAS Institute Inc., 2004) that accounted for the fixed effects of treatment, time, and their interaction. Week entered the model as a repeated measure for starter intake, intake of ME, forage intake, $\mathrm{ADG}$, and $\mathrm{BW}$. Calf was considered a 
random effect and treatment, and week and treatment by week interaction as fixed effects. Autoregressive covariance structure was the best fit for these data as determined by the lowest Akaike's information criterion. Initial $\mathrm{BW}$ was considered a covariate for the $\mathrm{BW}$ (d 36, 48, 54, 60, and 90). Before analyses, all data were screened for normality using the UNIVARIATE procedure of SAS, and any parameter that was not normally distributed was logarithmically transformed. Data on ruminal fermentation characteristics (d 36, 48, and 54) and data obtained from slaughtered animals were analyzed as a complete randomized design from dietary treatments. Least squares means for treatment effects were separated by the use of the PDIFF statement when the overall $F$-test was $P \leq 0.05$. Trends were declared when $P \leq 0.10$.

\section{RESULTS}

\section{Intake and Growth}

Intake of milk replacer, starter feed, ME, and BW are presented in Figure 1. Milk replacer intake was affected by a treatment $\times$ week interaction (Figure 1A; $P<$ $0.001)$, where abruptly weaned calves received more $(P$ $<0.001)$ milk replacer than gradually weaned calves. During the $10 \mathrm{~d}$ step-down, gradually weaned calves consumed approximately 1.8 times more starter feed than those weaned abruptly (Figure 1B; $P<0.05$ ). However, starter feed intake did not differ between dietary treatments in the week following weaning (Table 1). The difference in ME intake between the treatment groups was most apparent during the week of stepdown (Figure 1B), with abruptly weaned calves receiving more ME than gradually weaned calves (Table 1; $P=0.05)$.

Initial BW was similar for calves between dietary treatments, with calves weighing on average $42.96 \pm$ $1.18 \mathrm{~kg}$ (Table 1). A treatment $\times$ week interaction was observed for BW at d 48 of the study and abruptly weaned calves had higher BW than those weaned gradually at d 48 (Figure 1D; $P<0.001$ ). No treatment effect was observed for BW in the week following weaning on d 54 and on d 60 and 90 for heifers. Intake of chopped straw was greater in gradually weaned calves than those weaned abruptly during the preweaning period $(P=0.007)$; however, chopped straw intakes were not different among treatments during the last week of the experiment ( 48 to $54 \mathrm{~d}$ ). Average total gain and ADG during the preweaning period (until d 48 of the study) were similar between dietary treatments; however, calf growth was significantly greater in gradually weaned calves than those weaned abruptly in the $6 \mathrm{~d}$ following weaning (Table $1 ; P<0.01$ ).

\section{Rumen Fermentation, Blood BHB, and Fecal Starch}

Ruminal $\mathrm{pH}$ values did not differ between treatments (Table 2). The concentration of total VFA, acetate, and propionate in rumen fluid were greater for gradually weaned calves than those weaned abruptly at d 48 of the study $(P<0.01)$, but no differences were observed in the concentrations of both total and individual VFA between dietary treatments in d 36 and 54 of the study (Table 2). Despite the differences in VFA concentration, the concentrations of butyrate were not affected by treatment in d 36, 48, and 54 of the study.

Gradually weaned calves had greater concentration of BHB in the blood than those weaned abruptly $(P<$ 0.01), although BHB concentrations were similar between dietary treatments in d 36 and 54 of study (Table 2 ). No differences were present in fecal starch percentage between treatment groups at $\mathrm{d} 36$, a tendency to be lower on d $48(P=0.09)$, and significantly higher fecal starch on d 54 (Table 2; $P=0.05$ ) in abruptly weaned calves compared with those weaned gradually.

\section{Gastrointestinal Development}

Gastrointestinal development data are shown in Table 3. No differences were observed in the empty weight of rumen between treatment groups; however, the weight of the full rumen was greater in gradually weaned calves than those weaned abruptly $(P=0.02)$. No differences were found among treatments in the empty and full weights of omasum, abomasum, cecum, small intestine, and large intestine. Also, no differences were observed in length of small intestine, large intestine, and cecum between treatment groups. The weights of the forestomach, hind gut, liver, pancreas, kidney, spleen, visceral fat, and BW (at d 54) were similar between dietary treatments. In addition, rumen papillae morphology from the ventral sac displayed no differences in papillae length and width measurements. In agreement with the stereology measurements, the surface area, as determined by micro-CT, showed a numerical increase in step-down calves compared with abruptly weaned calves; however, these differences were not significant.

\section{DISCUSSION}

This study investigated feed intake, growth, and biomarkers of gastrointestinal development in calves fed an elevated plane of nutrition that were either weaned abruptly or using a step-down method. Our hypothesis was that calves fed elevated plane of nutrition and weaned gradually consume more energy in solid feed intake and have less weight loss during postweaning 


\section{$\infty-$ Gradual \\ Abrupt}

A

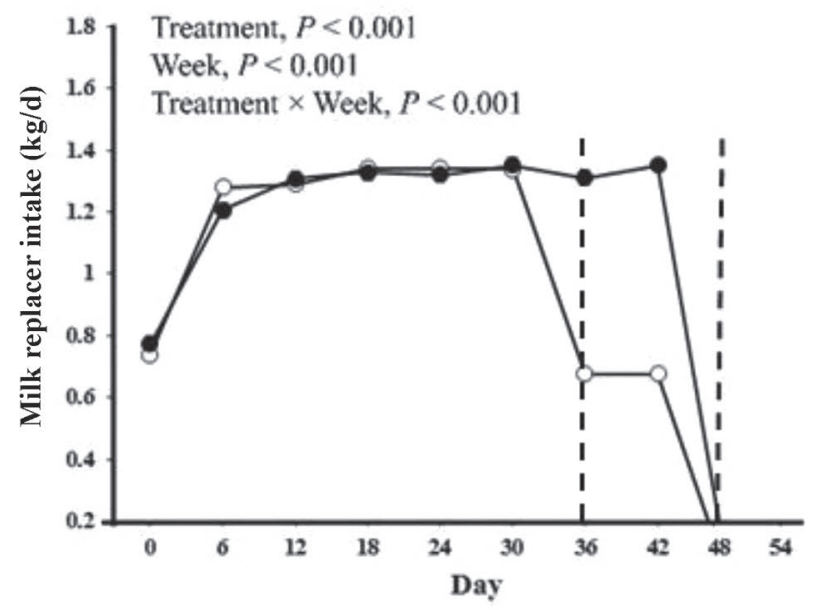

C

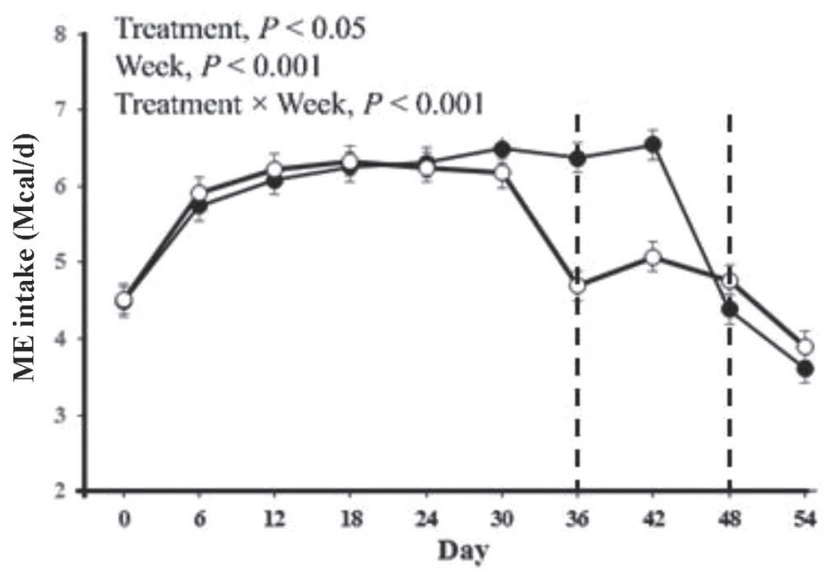

B

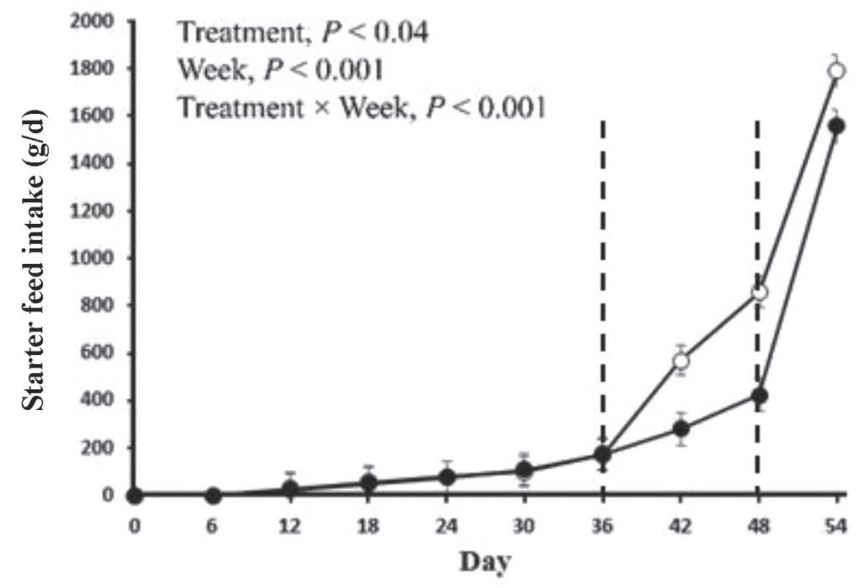

D

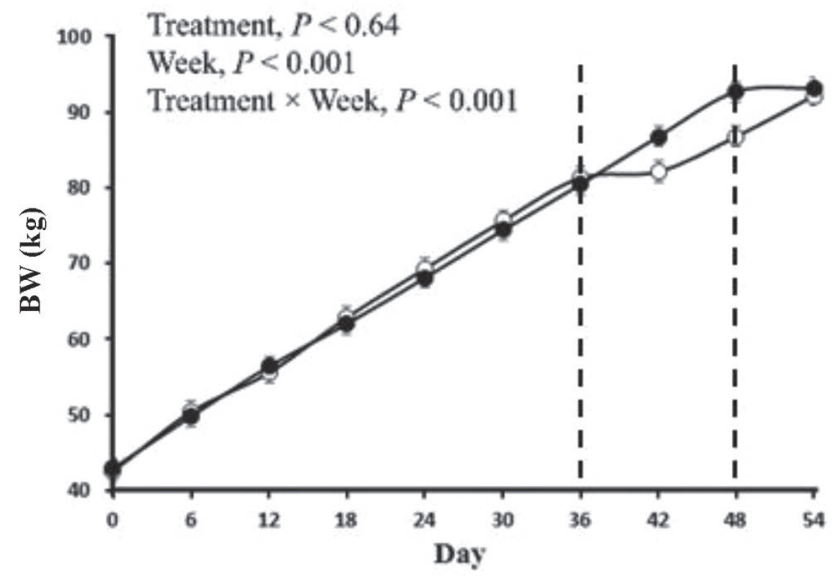

Figure 1. Summary of mean (A) milk replacer intake (kg/d), (B) starter feed intake (g/d), (C) ME intake (Mcal/d), and (D) BW (kg) of dairy calves fed high plane of nutrition and weaned on d 48 abruptly or gradually. Error bars indicate SEM for the treatment $\times$ week interaction. The step-down (d 36) and day of weaning (d 48) are depicted as dotted lines.

through more rapid development of the ruminal gastrointestinal tract. The abruptly weaned calves had higher growth rates preweaning; however, step-down calves had higher growth rates immediately after weaning. The abruptly weaned calves reduced their starter and ME intake, as well as BW compared with gradually weaned calves. However, the overall reduction in solid feed intake recovered faster compared with a similar study by Sweeney et al. (2010), where calves were weaned from 10 to $0 \mathrm{~L}$ on d 42 of life. The age of the calves in the current study to implement the step-down procedure was 1 wk older than in Sweeney et al. (2010), which may explain the difference in results. It has recently been shown that calves weaned at $56 \mathrm{~d}$ compared with $42 \mathrm{~d}$ can double their growth rates in the week immediately postweaning and display more indicators of ruminal fermentation and microbiological readiness to wean (Eckert et al., 2015; Meale et al., 2016).

Conventional milk feeding schemes restrict milk allocation to approximately $10 \%$ of BW in 2 meals per day, which causes the calf to increase starter intake earlier in life and facilitates a smoother transition in the development of digestive function during weaning (Baldwin et al., 2004). Preweaning starter intake has been used as a metric to determine when it is suitable to wean calves (Greenwood et al., 1997; Stamey et al., 2012). Although these strategies may have been adequate for conventionally fed calves, a shift in the industry toward 
Table 1. Effects of gradual weaning of calves fed high planes of nutrition on BW, starter feed intake, ME intake, chopped straw intake, and ADG

\begin{tabular}{|c|c|c|c|c|}
\hline \multirow[b]{2}{*}{ Item } & \multicolumn{2}{|c|}{ Treatment } & \multirow[b]{2}{*}{ SEM } & \multirow[b]{2}{*}{$P$-value } \\
\hline & Gradual & Abrupt & & \\
\hline \multicolumn{5}{|l|}{$\overline{\mathrm{BW}(\mathrm{kg})}$} \\
\hline Birth & 43.9 & 42.1 & 1.18 & 0.46 \\
\hline d 36 & 81.3 & 80.5 & 0.87 & 0.63 \\
\hline d 48 & 86.8 & 92.6 & 1.04 & $<0.01$ \\
\hline d 54 & 92.0 & 93.0 & 1.15 & 0.67 \\
\hline \multicolumn{5}{|l|}{ Starter intake $(\mathrm{g} / \mathrm{d})$} \\
\hline d 0 to 36 & 87.8 & 86.0 & 6.47 & 0.37 \\
\hline d 37 to 48 & 533.4 & 292.7 & 29.5 & 0.01 \\
\hline d 49 to 54 & $1,323.4$ & 990.7 & 74.3 & 0.01 \\
\hline \multicolumn{5}{|l|}{ ME intake (Mcal/d) } \\
\hline d 0 to 36 & 5.73 & 5.96 & 0.06 & 0.16 \\
\hline d 37 to 48 & 4.85 & 5.77 & 0.01 & 0.03 \\
\hline d 49 to 54 & 4.37 & 4.09 & 0.02 & 0.90 \\
\hline \multicolumn{5}{|c|}{ Chopped straw intake $(\mathrm{g} / \mathrm{d})$} \\
\hline d 0 to 36 & 6.10 & 3.70 & 0.45 & 0.08 \\
\hline d 37 to 48 & 34.64 & 18.12 & 1.98 & $<0.01$ \\
\hline d 49 to 54 & 62.09 & 52.44 & 4.14 & 0.05 \\
\hline \multicolumn{5}{|l|}{$\mathrm{ADG}(\mathrm{kg} / \mathrm{d})$} \\
\hline d 0 to 36 & 1.13 & 1.04 & 0.04 & 0.26 \\
\hline d 37 to 48 & 0.62 & 1.01 & 0.04 & 0.01 \\
\hline d 49 to 54 & 0.83 & 0.22 & 0.06 & 0.02 \\
\hline Average total gain (kg) & 49.2 & 50.2 & 0.93 & 0.60 \\
\hline
\end{tabular}

Table 2. Effects of gradual weaning of calves fed high planes of nutrition on rumen fermentation, blood BHB, and fecal starch

\begin{tabular}{|c|c|c|c|c|}
\hline \multirow[b]{2}{*}{ Item } & \multicolumn{2}{|c|}{ Treatment } & \multirow[b]{2}{*}{ SEM } & \multirow[b]{2}{*}{$P$-value } \\
\hline & Gradual & Abrupt & & \\
\hline \multicolumn{5}{|c|}{ Rumen pH } \\
\hline d 36 & 6.30 & 6.10 & 0.09 & 0.27 \\
\hline d 48 & 6.22 & 6.32 & 0.06 & 0.40 \\
\hline d 54 & 5.89 & 5.82 & 0.07 & 0.63 \\
\hline \multicolumn{5}{|c|}{ Total VFA $(\mathrm{m} M)$} \\
\hline d 36 & 36.9 & 39.7 & 2.4 & 0.57 \\
\hline d 48 & 59.8 & 45.0 & 2.2 & $<0.01$ \\
\hline d 54 & 71.1 & 73.6 & 2.8 & 0.67 \\
\hline \multicolumn{5}{|c|}{ Acetate $(\mathrm{m} M)$} \\
\hline d 36 & 22.2 & 22.8 & 1.5 & 0.85 \\
\hline d 48 & 30.5 & 24.8 & 1.1 & $<0.01$ \\
\hline d 54 & 35.2 & 35.8 & 1.3 & 0.81 \\
\hline \multicolumn{5}{|c|}{ Propionate $(\mathrm{m} M)$} \\
\hline d 36 & 10.4 & 11.9 & 0.7 & 0.31 \\
\hline d 48 & 21.2 & 13.2 & 1.0 & $<0.01$ \\
\hline d 54 & 26.3 & 27.2 & 1.4 & 0.74 \\
\hline \multicolumn{5}{|c|}{ Butyrate $(\mathrm{m} M)$} \\
\hline d 36 & 4.4 & 5.0 & 0.4 & 0.50 \\
\hline d 48 & 8.1 & 7.0 & 0.5 & 0.28 \\
\hline d 54 & 9.7 & 10.6 & 0.6 & 0.48 \\
\hline \multicolumn{5}{|c|}{ Blood BHB (mg/dL) } \\
\hline d 36 & 68.9 & 65.3 & 6.6 & 0.79 \\
\hline $\mathrm{d} 48$ & 145.0 & 81.8 & 9.2 & $<0.01$ \\
\hline d 54 & 295.0 & 249.9 & 17.0 & 0.19 \\
\hline \multicolumn{5}{|c|}{ Fecal starch (\%) } \\
\hline d 36 & 0.88 & 0.74 & 0.08 & 0.51 \\
\hline $\mathrm{d} 48$ & 1.69 & 0.95 & 0.22 & 0.09 \\
\hline
\end{tabular}


Table 3. Effects of abrupt or gradual weaning of calves fed high planes of nutrition on BW, gastrointestinal weights, and rumen $\mathrm{pH}$ and morphology on $\mathrm{d} 55$ of life

\begin{tabular}{|c|c|c|c|c|}
\hline \multirow[b]{2}{*}{ Item } & \multicolumn{2}{|c|}{ Treatment } & \multirow[b]{2}{*}{ SEM } & \multirow[b]{2}{*}{$P$-value } \\
\hline & Gradual & Abrupt & & \\
\hline Live BW (kg) & 94.1 & 94.8 & 1.3 & 0.79 \\
\hline Forestomach $(\mathrm{kg})$ & 10.55 & 8.37 & 0.52 & 0.03 \\
\hline Hindgut $(\mathrm{kg})$ & 6.73 & 6.39 & 1.52 & 0.59 \\
\hline Rumen full $(\mathrm{kg})$ & 7.83 & 6.02 & 0.42 & 0.02 \\
\hline Rumen empty (kg) & 1.51 & 1.40 & 0.06 & 0.42 \\
\hline Omasum full (kg) & 0.53 & 0.44 & 0.02 & 0.18 \\
\hline Omasum empty (kg) & 0.44 & 0.38 & 0.02 & 0.07 \\
\hline Abomasum full (kg) & 2.23 & 2.12 & 0.14 & 0.73 \\
\hline Abomasum empty (kg) & 0.61 & 0.57 & 0.02 & 0.44 \\
\hline Small intestine full (kg) & 4.41 & 3.95 & 0.15 & 0.12 \\
\hline Small intestine empty (kg) & 2.55 & 2.22 & 0.09 & 0.07 \\
\hline Small intestine length $(\mathrm{cm})$ & 2,598 & 2,495 & 53 & 0.35 \\
\hline Cecum full (kg) & 0.75 & 0.78 & 0.05 & 0.78 \\
\hline Cecum empty (kg) & 0.22 & 0.24 & 0.01 & 0.39 \\
\hline Cecum length $(\mathrm{cm})$ & 73.2 & 72.2 & 3.6 & 0.89 \\
\hline Large intestine full (kg) & 1.18 & 1.20 & 0.08 & 0.91 \\
\hline Large intestine empty (kg) & 0.66 & 0.70 & 0.03 & 0.56 \\
\hline Large intestine length $(\mathrm{cm})$ & 351 & 360 & 12 & 0.70 \\
\hline Rumen $\mathrm{pH}$ & 5.46 & 5.37 & 0.04 & 0.27 \\
\hline Rumen papillae length $(\mathrm{cm})$ & 2.60 & 2.46 & 0.19 & 0.34 \\
\hline Rumen papillae width $(\mathrm{cm})$ & 0.57 & 0.54 & 0.06 & 0.42 \\
\hline Rumen papillae surface area $\left(\mathrm{cm}^{2}\right)$ & 741 & 682 & 119 & 0.67 \\
\hline Rumen papillae density (papillae $/ \mathrm{cm}^{2}$ ) & 132 & 123 & 98 & 0.82 \\
\hline
\end{tabular}

elevated milk feeding and accelerated growth programs mean the same strategies may no longer be successful. To optimize the benefits of these accelerated programs, step-down milk feeding protocols become critical in facilitating a smooth transition at weaning. Compared with other weaning studies in dairy calves, the current study has the most abrupt step-down protocol in the literature, with calves fed 2 times per day, a rate in line with the most commonly practiced milk feeding frequency in North America (Vasseur et al., 2010). Calves were also fed the largest meal sizes and weaned at $\mathrm{d}$ 48 , which is early compared with other calves fed an elevated plane of nutrition preweaning.

The abruptness of the step-down approach in the current experiment caused a depression in growth, which was more severe compared with that postweaning in this treatment group (Figure 1B). A similar growth depression has been shown after the step-down period when milk is reduced by $50 \%$ in calves (Khan et al., 2007). The sharp reduction in growth, which is likely a consequence of the dramatic decrease in ME supply in response to the abrupt step-down, suggests that using automated technologies that facilitate the gradual daily reduction in milk allotment based on solid feed intake (de Passillé and Rushen, 2016) may optimize the transition process. Regardless of the weaning approach, no treatment differences were present in postweaned BW at d 54, or on d 60 and 90 thereafter in heifers. It is important to note that on d 55 the gradually weaned calves had greater rumen and forestomach full weights, therefore immediately after weaning the proportion of the BW growth is influenced by gut fill rather than tissue. Nevertheless, the step-down protocol used less milk but achieved the same growth; this is an economical and effective feeding scheme to improve postweaning growth.

To assess ruminal development in the current study, ruminal concentrations of VFA and blood BHB were determined pre- and post-step-down and weaning. As expected, the ruminal propionate and acetate concentrations of gradually weaned calves the day before weaning were greater than those for the abruptly weaned calves, indicating more microbial fermentation within the rumen before weaning. The end products of microbial fermentation, namely butyrate and propionate, are well-known stimulators of ruminal epithelial growth (Sakata and Tamate, 1978). The major pathway for VFA metabolism in the rumen epithelium is ketogenesis (Leighton et al., 1983), the conversion of butyric acid into BHB. Because this BHB can be easily measured in blood, this has recently been tested as a method for estimating calf feed intake, ruminal fermentation, and readiness to wean (Deelen et al., 2016). The $\mathrm{BHB}$ results of the current experiment suggest that the step-down influenced ruminal fermentation, because higher plasma BHB is significantly higher at $48 \mathrm{~d}$ in the gradual compared with abrupt weaning treatment (Table 2). Because this difference in BHB was at the 
time when half of the milk replacer had been removed, this response could be interpreted as an increase in ruminal starter fermentation. After weaning was completed, few differences were detected in rumen parameters between treatments, which indicates (1) that there is little carry-over effect of increased ruminal fermentation preweaning in ruminal fermentation markers in postweaned, step-down calves, and (2) that calves can rapidly shift ruminal fermentation when weaned abruptly at d 48 of life without depression of intake. The rapid shift in feed intake and ruminal fermentation observed for the abruptly weaned calves suggests that they would be more susceptible to ruminal acidosis (Steele et al., 2016). Ruminal spot samples analyzed for $\mathrm{pH}$ showed higher values than other studies, with no samples reaching acute levels of acidosis $(\mathrm{pH}<5.0)$. Care must be taken when interpreting ruminal $\mathrm{pH}$ and concentrations from spot samples using a Geishauser probe due to potential saliva contamination does not represent the gold standard of continuous ruminal $\mathrm{pH}$ measurements (Duffield et al., 2004). More research is needed to further characterize how ruminal fermentation and continuous $\mathrm{pH}$ regulates ruminal development, feed intake, and performance during the weaning process.

To determine if the gradual weaning protocol altered digestive tract physiology after weaning, bull calves were killed at $6 \mathrm{~d}$ postweaning (d 55). The most noteworthy difference in the dissection data was that the full rumen was on average $1.8 \mathrm{~kg}$ heavier in calves that were gradually weaned. This greater weight, of which only $0.1 \mathrm{~kg}$ was rumen tissue, indicates that the numerical difference in starter intake (Table 1) at d 54 accumulated in the rumen as substrate for microbial fermentation, which would generate a greater nutrient pool, and thus greater levels of VFA to support growth and the transition to solid feed (Hall et al., 2015). The morphology of the rumen papillae showed no differences between treatments for rumen papillae length, width, density, and 3-dimensional surface morphology between groups. This was not expected as the dietary treatment was severe compared with other studies that have shown differences in rumen papillae morphology through butyrate supplementation (Gorka et al., 2009, 2011), hay supplementation, and weaning strategies (Khan et al., 2011). This lack of difference in rumen papillae is perhaps attributed to the time of sampling, as abruptly weaned calves in this study had $6 \mathrm{~d}$ to adapt postweaning before sampling. The exponential growth of rumen tissue mass after weaning has been previously documented in calves fed conventional diets during the days postweaning (Baldwin et al., 2004). In accelerated milk feeding protocols, such rumen papillae growth can be even more dramatic because the swing in DMI is typically higher (Khan et al., 2007). The lack of differences in rumen morphology between treatments postweaning is further supported by a lack of microbial changes, as previously reported from this experiment (Meale et al., 2016). Although large differences were present between ruminal bacterial diversity and community structure from pre- to postweaning, weaning strategy had a minimal effect on the microbiota. These results suggest that despite clear differences preweaning in ruminal fermentation parameters, adaptations in ruminal structure and microbiology are very rapid during weaning.

In the lower gut, no differences were observed in the weight of gut segments despite large differences in fecal starch concentrations. These concentrations were used as an indicator of total digestive tract starch digestibility, which is common in dairy cattle (Fredin et al., 2014). A decrease in fecal starch in dairy cows is associated with increased feed efficiency and milk production (Firkins et al., 2001). Fecal starch is not routinely used as a reliable marker of starch digestion in preweaned calves; however, it has been shown to be an effective marker of postweaning starch digestion (Dennis et al., 2016). In the current experiment, the fecal starch percentages were low in the preweaning phase (d 36 of life) because starter intake would have made up a relatively small proportion of intake. The treatment response was greatest postweaning, when fecal starch exceeded 5\% in the abruptly weaned group, similar to high values reported in the functional ruminant (Fredin et al., 2014). This may reflect an increased passage rate of feed material from the rumen, or a lack of gastrointestinal tract and microbial adaptation to digest the starch between treatments, despite similar postweaning starter intake. In lactating dairy cattle, the fecal starch levels as reported in the current experiment are associated with elevated fecal LPS and systemic inflammation of the gut (Khafipour et al., 2009; Li et al., 2012). Elevations in whole animal inflammatory cytokines have also been observed during weaning in Holstein bull calves (Kim et al., 2011), whereas weaning has been associated with increased gut permeability in calves fed an elevated plane of nutrition (Wood et al., 2015). The lower gut, and in particular the hindgut, may have impaired function and permeability during weaning, thereby drawing additional energy to mount an inflammatory response at the expense of growth. The lower gut plays a significant role in host function in monogastrics (Steele et al., 2016); however, research on digestive tract physiology during weaning has focused on the rumen, and as such, there remains a paucity of information on the effects of weaning on the lower gut in ruminants. 


\section{CONCLUSIONS}

In this study we demonstrated the benefits of a step-down protocol at weaning with respect to growth and feed efficiency in calves fed an elevated plane of nutrition in 2 meals per day. However, the step-down protocol in this experiment was associated with a reduction in energy intake, which suggests opportunities to improve step-down weaning protocols commonly used in the dairy industry. Minimal differences in rumen morphology and ruminal biomarkers were detected postweaning, which indicates that calves can adapt their digestive physiology swiftly to accommodate the change in nutrient type. Furthermore, the elevated levels of fecal starch suggest that ruminal digestion and lower gut function may be impaired, as well as explain the depressed growth and health evident during abrupt weaning. The results of this study reinforce the importance of precision when feeding weaned calves an elevated plane of nutrition and will lead to new feeding strategies to improve animal growth, health, and welfare.

\section{ACKNOWLEDGMENTS}

The authors acknowledge the technical assistance provided by Curt Bossuyt and Daniel Fournier (Nutreco Canada Inc.), Javier Martin-Tereso and Lot Bos (Trouw Nutrition Research and Development), Doug Waterman, Carolyn Innes, and Stephen Elgersma (Trouw Nutrition Agresearch), as well as Morteza Hosseini Ghaffari (University of Alberta).

\section{REFERENCES}

Baldwin, R. L., VI, K. R. McLeod, J. L. Klotz, and R. N. Heitmann. 2004. Rumen development, intestinal growth and hepatic metabolism in the pre- and postweaning ruminant. J. Dairy Sci. 87(E. Suppl.):E55-E65.

Benschop, D. L., and J. P. Cant. 2009. Developmental changes in clearance of intravenous doses of glucose, acetate and $\beta$-hydroxybutyrate from plasma of calves. Livest. Sci. 122:177-185. http://dx.doi.org/ https://doi.org/10.1016/j.livsci.2008.08.011.

Canadian Council on Animal Care. 2009. Guidelines on the Care and Use of Farm Animals in Research, Teaching and Testing. Canadian Council on Animal Care, Ottawa, ON, Canada.

Deelen, S. M., K. E. Leslie, M. A. Steele, E. Eckert, H. E. Brown, and T. J. DeVries. 2016. Validation of a calf-side $\beta$-hydroxybutyrate test and its utility for estimation of starter intake in dairy calves around weaning. J. Dairy Sci. 99:7624-7633. https://doi. org/10.3168/jds.2016-11097.

Dennis, T. S., H. Hu, F. X. Suarez-Mena, T. M. Hill, J. D. Quigley, and R. L. Schlotterbeck. 2016. Use of fecal starch as an indicator of starch digestibility and starter intake in preweaned dairy calves. J. Anim. Sci. 94:790-791.

de Passille, A. M., and J. Rushen. 2016. Using automated feeders to wean calves fed large amounts of milk according to their ability to eat solid feed. J. Dairy Sci. 99:3578-3583. https://doi.org/10.3168/ jds.2015-10259.
Duffield, T., J. C. Plaizier, A. Fairfield, R. Bagg, G. Vessle, P. Dick, J. Wilson, J. Aramini, and B. McBride. 2004. Comparison of techniques for measurement of rumen $\mathrm{pH}$ in lactating dairy cows. J. Dairy Sci. 87:59-66.

Eckert, E., H. E. Brown, K. E. Leslie, T. J. DeVries, and M. A. Steele. 2015. Weaning age affects growth, feed intake, gastrointestinal development and behaviour in Holstein calves fed an elevated plane of nutrition during the preweaning stage. J. Dairy Sci. 98:63156326. https://doi.org/10.3168/jds.2014-9062.

Firkins, J. L., M. L. Eastridge, N. R. St-Pierre, and S. M. Noftsger. 2001. Effects of grain variability and processing on starch utilization by lactation dairy cattle. J. Anim. Sci. 79:218-238. https:// doi.org/10.2134/jas2001.79E-SupplE218x.

Fredin, S. M., L. F. Ferraretto, M. S. Akins, P. C. Hoffman, and R. D. Shaver. 2014. Fecal starch as an indicator of total-tract starch digestibility by lactating dairy cows. J. Dairy Sci. 97:1862-1871. https://doi.org/10.3168/jds.2013-7395.

Geishauser, T. 1993. An instrument for collection and transfer of ruminal fluid and for administration of water soluble drugs in adult cattle. Bovine Pract. 27:38-42.

Gorka, P., Z. M. Kowalski, P. Pietrzak, A. Kotunia, W. Jagusiak, and R. Zabielski. 2011. Is rumen development in newborn calves affected by different liquid feeds and small intestine development? J. Dairy Sci. 94:3002-3013. https://doi.org/10.3168/jds.2010-3499.

Gorka, P., Z. M. Kowalski, P. Pietrzak, A. Kotunia, R. Kiljanczyk, J. Flaga, J. J. Holst, P. Guilloteau, and R. Zabielski. 2009. Effect of sodium butyrate supplementation in milk replacer and started diet on rumen development in calves. J. Physiol. Pharmacol. 60:47-53.

Green, B. L., B. W. McBride, D. Sandals, K. E. Leslie, R. Bagg, and P. Dick. 1999. The impact of a monensin controlled-release capsule on subclinical ketosis in the transition dairy cow. J. Dairy Sci $82: 333-342$.

Greenwood, R. H., J. L. Morrill, and E. C. Titgemeyer. 1997. Using dry feed intake as a percentage of initial body weight as a weaning criterion. J. Dairy Sci. 80:2542-2546.

Hall, M. B. 2009. Analysis of starch, including maltooligosaccharides in animal feeds: A comparison of methods and a recommended method for AOAC collaborative study. J. AOAC Int. 92:42-49.

Hall, M. B., T. D. Nennich, P. H. Doane, and G. E. Brink. 2015. Total volatile fatty acid concentrations are unreliable estimators of treatment effects on ruminal fermentation in vivo. J. Dairy Sci. 98:3988-3999.

Khafipour, E., S. Li, J. C. Plaizier, and D. O. Krause. 2009. Rumen microbiome composition determined using two nutritional models of subacute ruminal acidosis. Appl. Env. Microbiol. 75:7115-7124.

Khan, M. A., A. Bach, D. M. Weary, and M. A. G. von Keyserlingk. 2016. Invited review: Transitioning from milk to solid feed in dairy heifers. J. Dairy Sci. 99:885-902. https://doi.org/10.3168/ jds.2015-9975.

Khan, M. A., H. J. Lee, W. S. Lee, H. S. Kim, S. B. Kim, K. S. Ki, J. K. Ha, H. G. Lee, and Y. J. Choi. 2007. Pre- and postweaning performance of Holstein female calves fed milk through step-down and conventional methods. J. Dairy Sci. 90:876-885. https://doi. org/10.3168/jds.S0022-0302(07)71571-0.

Khan, M. A., D. M. Weary, and M. A. G. von Keyserlingk. 2011. Invited review: Effects of milk ration on solid feed intake, weaning, and performance in dairy heifers. J. Dairy Sci. 94:1071-1081. https://doi.org/10.3168/jds.2010-3733.

Kim, M. H., J. Y. Yang, S. D. Upadhaya, H. J. Lee, C. H. Yun, and J. K. Ha. 2011. The stress of weaning influences serum levels of acute-phase proteins, iron-binding proteins, inflammatory cytokines, cortisol, and leukocyte subsets in Holstein calves. J. Vet. Sci. 12:151-157. https://doi.org/10.4142/jvs.2011.12.2.151.

Leighton, B., A. R. Nicholas, and C. I. Pogson. 1983. The pathway of ketogenesis in rumen epithelium of the sheep. Biochem. J. 216:769-772.

Li, S., E. Khafipour, D. O. Krause, A. Koreker, J. C. RodriguezLecompte, G. N. Gozho, and J. C. Plaizier. 2012. Effects of subacute ruminal acidosis challenges on fermentation and endotoxins in the rumen and hindgut of dairy cows. J. Dairy Sci. 95:294-303. https://doi.org/10.3168/jds.2011-4447. 
McGuirk, S. M., and S. F. Peek. 2014. Timely diagnosis of dairy calf respiratory disease using a standardized scoring system. Anim. Health Res. Rev. 15:145-147.

Meale, S. J., S. Li, P. Azevedo, H. Derakhshani, J. C. Plaizier, E. Khafipour, and M. A. Steele. 2016. Development of ruminal and fecal microbiomes are affected by weaning but not weaning strategy in dairy calves. Front. Microbiol. 7:582. https://doi.org/10.3389/ fmicb.2016.00582.

Sakata, T., and H. Tamate. 1978. Rumen epithelial cell proliferation accelerated by rapid increase in intraruminal butyrate. J. Dairy Sci. 61:1109-1113.

SAS Institute Inc. 2004. SAS/STAT User's Guide. Release 9.1. SAS Inst. Inc., Cary, NC.

Soberon, F., E. Raffrenato, R. W. Everett, and M. E. Van Amburgh. 2012. Preweaning milk replacer intake and effects on long-term productivity of dairy calves. J. Dairy Sci. 95:783-793. https://doi. org/10.3168/jds.2011-4391.

Stamey, J. A., N. A. Janovick, A. F. Kertz, and J. K. Drackley. 2012. Influence of starter protein content on growth of dairy calves in an enhanced early nutrition program. J. Dairy Sci. 95:3327-3336. https://doi.org/10.3168/jds.2011-5107.

Steele, M. A., F. Garcia, M. Lowerison, J. A. Metcalf, and M. Hurtig. 2014. Technical note: Three-dimensional imaging of rumen tissue for morphometric analysis using micro-computed tomography. J. Dairy Sci. 97:7691-7696. https://doi.org/10.3168/jds.2014-8374.

Steele, M. A., G. B. Penner, F. Chaucheyras-Durand, and L. L. Guan. 2016. Development and physiology of the rumen and the lower gut: Targets for improving gut health. J. Dairy Sci. 99:4955-4966. https://doi.org/10.3168/jds.2015-10351.

Sweeney, B. C., J. Rushen, D. M. Weary, and A. M. De Passille. 2010. Duration of weaning, starter intake and weight gain of dairy calves fed large amount of milk. J. Dairy Sci. 93:148-152. https://doi. org/10.3168/jds.2009-2427.

Vasseur, E., F. Borderas, R. I. Cue, D. Lefebvre, D. Pellerin, J. Rushen, K. M. Wade, and A. M. de Passille. 2010. A survey of dairy calf management practices in Canada that affect animal welfare. J. Dairy Sci. 93:1307-1315. https://doi.org/10.3168/jds.2009-2429.

Williamson, D. H., J. Mellanby, and H. A. Krebs. 1962. Enzymatic determination of $\mathrm{D}(-)-\beta$ hydroxybutyric acid and acetoacetic acid in blood. Biochem. J. 82:90-96.

Wood, K. M., S. I. Palmer, M. A. Steele, J. A. Metcalf, and G. B. Penner. 2015. The influence of age and weaning on permeability of the gastrointestinal tract in Holstein bull calves. J. Dairy Sci. 98:7226-7237. https://doi.org/10.3168/jds.2015-9393. 